\title{
Nurse Practitioner Coding Practices in Primary Care: A Retrospective Chart Review
}

\author{
Kymberly R. Allen, MS, RN \\ Caroline B. Reinke, MS, RN \\ Joanne M. Pohl, Ph D, RN, CS, FAAN \\ Kristy K. Martyn, Ph D, RN, CS, CPNP \\ Elaine P. Mclntosh, RN, CS, FNP
}

\section{Purpose}

To describe the coding and documentation practices of nurse practitioners (NPs) when using evaluation and management $(\mathrm{E} \& \mathrm{M})$ codes in an academic primary care center.

\section{Data Sources}

A randomized retrospective review of ten charts from a nurse-managed primary care clinic affiliated with a midwestern researchintensive university.

\section{Conclusuion}

The findings demonstrate that the documentation in the chart for six of the ten client encounters did not support the E \& M codes assigned by the clinicís NPs. Four of these six client encounters were overcoded; the remaining two encounters were undercoded.

\section{Implications for Practice}

Findings of this study support the need for additional education of NPs in the areas of coding and documentation.

\section{Key Words}

Coding; billing; nurse practitioner; reimbursement; legal issues; advanced practice nursing.

\section{Authors}

Kymberly R. Allen, MS, RN, was formerly a graduate student at the University of Michigan. Caroline B. Reinke, MS, RN, was formerly a graduate student at the University of Michigan. Joanne M. Pohl, Ph D, RN, CS, FAAN, is an Associate Professor and Associate Dean, Office of Community Partnerships, Kristy K. Martyn, $\mathrm{Ph} \mathrm{D}, \mathrm{RN}, \mathrm{CS}, \mathrm{CPNP}$, is an Assistant Professor, and Elaine P. McIntosh, RN, CS, FNP, is the Director of Nurse Managed Centers at the University of Michigan School of Nursing, Ann Arbor, MI. Contact Ms. Allen by email at kymallen@yahoo.com

\section{INTRODUCTION}

While the quality of care provided by nurse practitioners (NPs) has been well established in the literature (Mundinger et al., 2000; Neale, 1999; Safriet, 1992), limited data exist regarding how they "code" for the healthcare that they provide. Coding refers to the utilization of the Healthcare Financing Administration's (HCFA) (currently referred to as The Center for Medicare and Medicaid Services) guidelines to document the level of service for a client encounter for the purpose of billing for services. The codes established for this purpose were meant to diferentiate the complexity of care and reflect relative work values in the provision of services. Currently, the majority of relative work values are based on data provided from physicians.

The lack of information on NP coding practices is a consequence of reimbursement guidelines that existed prior to the Balanced Budget Act of 1997. Before the Balanced Budget Act of 1997, NPs provided and coded for healthcare services but were required to bill under a physician's reimbursement number (HCFA, 1998). Therefore, the services provided by NPs were hidden and embedded in the physicians' services in national practitioner databases. This "bundling" of services for reimbursement made it difficult to accurately distinguish which healthcare providers were providing which services (Rapsilber \& Anderson, 2000). Consequently, difficulty existed in differentiating NP coding practices from those of other healthcare providers.

The passage of the Balanced Budget Act of 1997 established new billing guidelines that allowed NPs to bill directly to and receive reimbursement from Medicaid, Medicare Part B, and some participating commercial insurances for primary care services within the limits of each state's laws (HCFA, 1998). The implementation of the Balanced Budget Act of 1997 has created a setting in which the healthcare services provided by NPs can be more accurately reflected (Rapsilber $\&$ Anderson, 2000). This information can now be used in healthcare research and policy to impact the future of NPs as providers of primary healthcare.

The Balanced Budget Act of 1997 offers NPs the opportunity to establish themselves as independent providers of primary healthcare. Thus, it is imperative that NPs have advanced knowledge of HCFA's guidelines related to coding and documentation for billing purposes. The relevance of coding correctly for healthcare services includes the generation of an accurate practice profile in national databases, the receipt of proper reimbursement, and a decreased risk of lawsuits (Buppert, 2001b).

As a result of the billing regulations prior to the Balanced Budget Act of 1997, limited data exist surrounding coding behaviors of NPs as individual providers. This article describes the coding and documentation practices of NPs when using the evaluation and management (E \& M) codes in an academic primary care center. 
Table 1. Key to Determining E \& M Code Level for Client Encounter

Clients

Require all three components within column

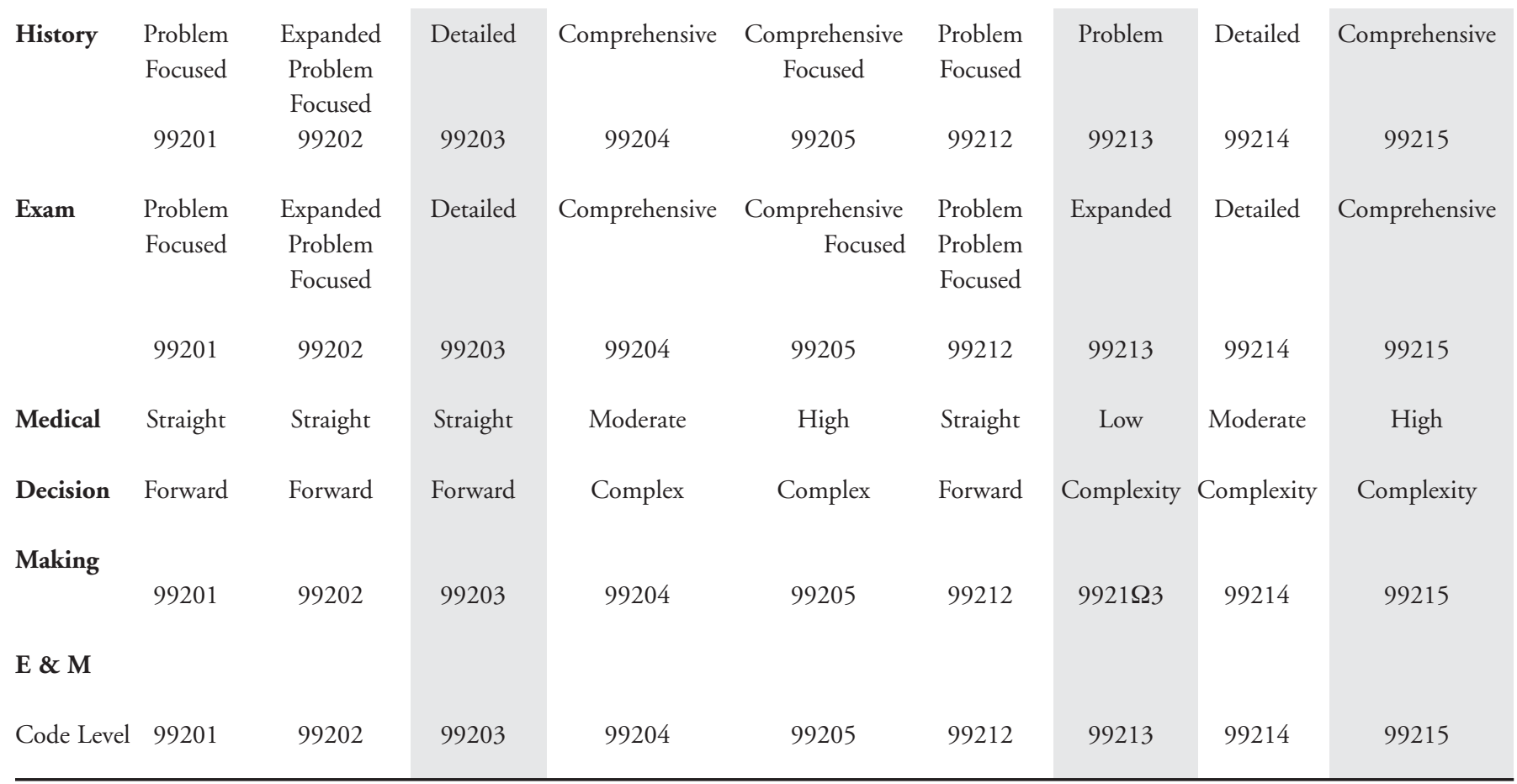

Note: Table 1 illustrates how a level of service is assigned to ambulatory client encounters. Shaded columns are the codes studied by Sullivan-Marx \& Maislin (2000).

\section{REVIEW OF LITERATURE}

A study by Sullivan-Marx and Maislin (2000) compared relative work values between NPs and family physicians for levels of service for three specific ambulatory E \& M codes. This pilot study examined the practicality of using NP data to determine relative work values in the Medicare Fee Schedule for three selected E \& M codes (99203, 99213, and 99215) (see Table 1). The results indicated no significant differences between NPs and family physicians in estimations of relative work values for each of the three levels of $\mathrm{E} \& \mathrm{M}$ codes.

A second study by Horner, Paris, Purvis, and Lawler (1991) compared the accuracy of billing and coding of faculty physicians, residents, family nurse practitioners (FNPs), and registered nurses (RNs). The purpose of this study was to determine billing codes for the level of service, diagnosis, and procedures by reviewing the progress notes in a client's chart. The reviewers were blinded to the actual billing forms. The results indicated that FNPs were comparable to the residents and faculty physicians in their accuracy of billing information. In addition, the results of the study suggested that all practitioners in this study were consistently undercoding. The recommendations of this study highlighted the need for additional instruction for all healthcare professionals involved in coding and billing.

Relevant findings from the above studies indicate that NPs have familiarity with relative work values and have undercoded for primary healthcare services. While these studies compared the coding and billing practices of different types of primary care providers, the purpose of this study evaluated the coding and documentation practices of NPs in a midwestern university affiliated nurse-managed center.

\section{METHODS}

Approval for the project was obtained from the Institutional Review Board of the associated university. Two NP graduate students completed the review. To prepare for the project, the investigators attended a two-hour seminar on documentation, coding, and billing and reviewed two leading publications that described HCFA's coding guidelines (Buppert, 1999; MedLearn, 2000). In addition, advanced practice nursing faculty with expertise in coding served as consultants.

The project consisted of a retrospective review of 10 randomly selected charts from a convenience sample of the clinic's charts. The inclusion criteria consisted of the following: 1) the presence of a signed consent form in the clinic which explained that information from the chart may be used for research purposes; 2) the encounters must have taken place at the clinic between January 1999 and December 1999; and 3) only charts of clients over 18 , mentally competent, and nonpregnant were reviewed. 
Table 2. Ambulatory E\&M Audit Tool

$\begin{array}{ll}\text { Client ID\#: } & \text { Sex: M F } \\ \text { Date of Birth: } & \text { Date of Encounter: } \\ \text { \# Visits/Year } & \text { \# Chronic Meds: } \\ \text { Consent Form: YN } & \text { Type of Insurance: }\end{array}$

\section{HISTORY:}

\section{HPI:}

Location

Quality

Severity

Duration

Timing

Context

Modifying Factors

Associated S/Sx's

\section{EXAM:}

\section{Body Areas:}

Head/Face

Neck

Chest/Breast/Axilla

Abdomen

Genitals/Groin

Back/Spine

Extremities

\section{ROS:}

Constitutional

Eyes

ENMT

Cardiovascular

Respiratory

GI

GU

Musculoskeletal
Investigator Code:

Clinician ID\#:

Marital Status:

PFSH:

Integument

Neurological

Psychiatric

Endocrine

Hematologic/Lymphatic

Allergic/Immunologic

\section{Past Hx}

illness, operations, injuries treatments

Family $\mathbf{H x}$

hereditary diseases

Social Hx

age appropriate review of past and current activities

\section{MEDICAL DECISION MAKING:}

\# Dx or Tx Options (may choose 1 or more)

Self-limited or minor

Est. problem to examiner; stable, improved

Est. problem to examiner; worsening

New Problem to examiner; no workup planned

New Problem to examiner; workup planned

Amount \& Complexity of Data (may choose 1 or more)

Review \&/or order of clinical lab tests

Review \&/or order of tests in radiology section of CPT

Review\&/or order of tests in Medicine section of CPT

Discussion of test results with performing MD

Decision to obtain old records \&/or obtain HX from someone

other than pt.

Review \& Summarization of old records \&/or obtain HX from someone other than pt. \&/or discussion of case with another healthcare provider

Independent visualization of image, tracing, or specimen itself

During the selection and review process, the investigators were blinded to the original $\mathrm{E} \& \mathrm{M}$ codes assigned by the clinic's NPs. To standardize the data collection process, audit tools based on The1997 Current Procedural Terminology were created by the investigators and used to conduct the reviews (see Table 2). The data collection involved recording each element of the participant encounter into the corresponding section of the appropriate audit tool. The investigators reviewed each participant encounter twice. Differences of opinion were resolved by consulting the documentation and coding references (Buppert, 1999; MedLearn, 2000). There were no differences of opinion that could not be clarified by a review of the guidelines. Next, a level of service was assigned to the encounter by utilizing the
Documentation Guidelines for Evaluation and Management for new and established clients in ambulatory settings (HCFA, 1998). Finally, following the review and determination of level of service for each participant encounter, the codes assigned by the investigators and the NPs were compared.

\section{FINDINGS}

Three FNPs provided the healthcare services for the 10 study participants. In accordance with state requirements, the NPs were Master's prepared and board certified. Their average experience as NPs was 14 years. The investigators and NPs assigned 
Table 3. E \& M Coding of Encounters by Nurse Practitioners and Investigators

$\begin{array}{llllll}\begin{array}{l}\text { Participant } \\ \text { Encounter }\end{array} & \text { History } & \text { Exam } & \begin{array}{l}\text { Decision- } \\ \text { Making }\end{array} & \begin{array}{l}\text { Investigator's } \\ \text { Code }\end{array} & \begin{array}{l}\text { NP's } \\ \text { Code }\end{array} \\ 1 & 99201 & 99205 & 99204 & 99201 & 99203 \\ 2 & 99202 & 99202 & 99204 & 99202 & 99203 \\ 3 & 99202 & 99202 & 99204 & 99213 \\ 4 & 99213 & 99212 & 99213 & 99213 \\ 5 & 99214 & 99213 & 99213 & 99213 \\ 6 & 99213 & 99213 & 99213 & 99213 & 99214 \\ 7 & 99213 & 99213 & 99213 & 99213 & 99385 \\ 8 & 99214 & 99214 & 99214 & 99214 & 99395 \\ 9 & 99214 & 99214 & 99213 & 99213 \\ 10 & 99214 & 99214 & 99214 & 99214 & 99214\end{array}$

Note. Columns 2 through 4 represent the 3 key components of each encounter that were used by investigators to assign the E \& M code.

the identical $\mathrm{E} \& \mathrm{M}$ code to four of the ten participant encounters (40\%). Six participant encounters were assigned different $\mathrm{E}$ $\& \mathrm{M}$ codes (60\%) (See Table 3).

Of the encounters that were coded differently, the NPs coded four at a higher level than investigators. Three of the encounters coded at a higher level by the NPs were for new client visits, while one was for an established client visit. The remaining two encounters that were coded differently were coded using only preventive medicine codes when both an E \& M code and a preventive medicine code were warranted. Therefore, these two encounters were considered undercoded.

The NPs coded three new client encounters (participants 1, 2 , and 3) at higher levels of service than was indicated during the chart review. One of these encounters (participant 3) was documented on a pre-printed physical exam checklist. The NP's documentation of the encounter of an established client (participant 7), met the requirements for an expanded problem focused level encounter (99213) rather than a detailed level encounter (99214). All aspects of the encounter (history, exam, and medical decision-making) were at an expanded problem focused level (99213). Thus, additional elements in at least two sections of the encounter would be needed for the encounter to meet the criteria of the next higher level of service that was assigned by the NP.

Finally, the NPs assigned the encounters (participants 8 and 9) preventive medicine codes (99385 and 99396). In each case, a chronic condition was addressed during the encounter, thus an E \& $M$ code along with a preventive medicine code should have also been assigned. The preexisting conditions for these two clients included multiple sclerosis, osteoporosis, menopause, and recurrent vaginitis. In addition, the code assigned to participant 8 was a new client preventive medicine code rather than an established client preventive medicine code. This particular participant had visited the clinic approximately seven times during the study period.

\section{DISCUSSION}

The findings from this preliminary study highlight four issues that merit consideration during the coding and documentation of ambulatory client encounters. First, three new client encounters were coded at higher levels of service than the review of documentation warranted. According to billing and coding experts, this is not an uncommon error (personal conversation, A. Alflen, Healthcare and Business Consultant for Grand Management Group, 3/20/01). Per HCFA guidelines, new client encounters require more documentation than established client encounters to qualify for the same levels of service (Buppert, 1999). Specifically, all three key components of a new client encounter (history, physical exam, and medical decision-making) must be 
at the same level in order to achieve a certain $\mathrm{E} \& \mathrm{M}$ code. If components are not documented at the same level, then the lowest level of the documented components must be assigned (MedLearn, 2000). For instance, the documentation in the chart (participant 1), met the requirements for a problem focused encounter (99201) rather than a detailed encounter (99203). The review of documentation for this encounter found that the exam was comprehensive (99205) and medical-decision making was moderately complex (99204), while the history portion was problem focused (99201). In order for this new client encounter to meet the criteria for the assigned code, the NP needed to document more elements of the history. For the purpose of discussion, it should be noted that if the participant had been an established patient at this clinic the documentation would have met the criteria for the level of code assigned by the NP.

Second, an established client was assigned a new client code. According to the HCFA guidelines summarized by Buppert (2001b), a new client is defined as one who has not had an encounter with the practice within the past three years; all other clients are considered established. This type of error can occur if the NP is rushed and simply checks off the incorrect box on the encounter form. It is also critical for office staff to pick up these sorts of unintentional errors. The insurer may well have rejected this claim. Paying close attention to encounter form details can eliminate this type of common error.

Third, two encounters were coded using preventive medicine codes when they also required an E \& M code. Preventive medicine codes alone are not appropriate:

"if an abnormality/ies is encountered or a preexisting condition is addressed in the process of performing a general preventive medicine evaluation, and if the problem/abnormality is significant enough to require additional work to perform the key components of a problem-oriented E/M service, then the appropriate Office/Outpatient code 99201-99215 should be reported in addition to the preventive medicine." (MedLearn, 2000), p. 84).

In each of the two encounters, a preexisting condition was addressed and thus an appropriate E \& M code should have been included. Reviewers therefore considered these encounters to be undercoded. This is a frequently misunderstood requirement of preventive medicine codes among healthcare practitioners (personal conversation, A. Alflen, Healthcare and Business Consultant for Grand Management Group, 3/20/01). Thus, the NP should have assigned a preventive medicine code and an E \& $M$ code for these two encounters.

Finally, one client encounter was documented on a pre-printed physical examination checklist. In order to meet the coding guidelines of the examination portion of an encounter, two elements from a body system must be documented. For example, the placement of a check next to the cardiac assessment to indicate a normal cardiac exam does not contribute to the overall level of the exam; however, the documentation of two specific findings, such as no murmur or regular rate, does contribute to the overall level of the exam (MedLearn, 2000). Thus, in this case all the NP needed to do was write out the findings and the encounter would have met the requirements for the assigned $\mathrm{E}$ $\& \mathrm{M}$ code.

\section{LIMITATIONS}

Although the findings from this study have limited generalizablilty due to the small sample size and setting, they do point out common and frequent coding errors. Future replication of this or similar studies with larger sample sizes is recommended. Secondly, the study setting was part of an academic center and may not be reflective of other settings such as an individual provider or a small group practice.

\section{CONCLUSION}

The findings support the need for additional preparation in the areas of documentation and coding for NPs. The investigators suggest that practicing NPs and NP students participate in documentation, billing, and coding educational programs. Additionally, NPs should have access to and be familiar with recent HCFA reference materials such as MedLearn or Documentation Guidelines for Evaluation and Management. These references clarify the documentation needed to establish an encounter's level of service. Moreover, most commercial payers adopt Medicare guidelines; therefore, NPs should arrange to receive the Medicare newsletter that provides updates on rules and regulations (Buppert, 2001a; Buppert 2001b).

The establishment of quality assurance programs for coding and billing within practices is recommended to self-monitor compliance with federal healthcare guidelines. One resource that can be used to establish compliance programs is Compliance Programs for Individual and Small Group Practices, published in 2000 by the Office of Inspector General. In the case of this primary care setting, NPs and their students received added content on coding following the conclusion of this project. A professional audit was then completed which supported a high level of accuracy in coding.

The use of documentation forms that reflect the current HCFA guidelines would be helpful in ensuring documentation of essential components of the history and exam. The use of such forms facilitates comprehensive and concise documentation that meets both established clinical guidelines and $\mathrm{E} \& \mathrm{M}$ code level criteria (Towers, Gillett, \& Goldblum, 2000). Examples of such forms can be found at The Nurse Practitioner website http://www.tnpj.com/documentation. If the adoption of new forms is not an option, a pocketsize reference titled Outpatient/Office Medical Billing Tool can be purchased from the NP Shoppe at npss@nurse.net. This reference lists the components necessary for each level of service.

In conclusion, it is imperative for NPs to distinguish their contributions to healthcare. The distinction of the services NPs provide is crucial so that NPs are no longer invisible providers of primary care (Neale, 1999; Pearson, 1999). The Balanced Budget Act of 1997 provides NPs the opportunity to differenti- 
ate the healthcare services they provide by allowing for independent billing. Appropriate knowledge and application of the HCFA guidelines can assist NPs in the establishment of accurate productivity profiles in national databases, the receipt of proper reimbursement for their services, and a decreased risk of legal consequences (Rapsilber \& Anderson, 2000).

In order to improve understanding of NP documentation and coding practices, future research is needed. The qualitative evaluation of documentation can provide insight into the coding behaviors of NPs. In addition, the development of user-friendly documentation and coding audit tools is important for the standardization of data collection during research. Moreover, the documentation, coding, and billing education within NP programs should be enhanced with the addition of courses on healthcare systems, policy, and finance to ensure that NPs are receiving adequate preparation for future practice.

\section{References}

Buppert, C. (1999). Nurse practitioner's business practice \& legal guide. Annapolis, MD: Aspen Publishers.

Buppert, C. (2001a). Avoiding Medicare fraud, part 1. The Nurse Practitioner, 26 (1), 70-5.

Buppert, C. (2001b). Avoiding Medicare fraud, part 2. The Nurse Practitioner, 26

(2), 34, 36-38, 41.

Health Care Financing Administration (HCFA). (1998). Increased Medicare pay-

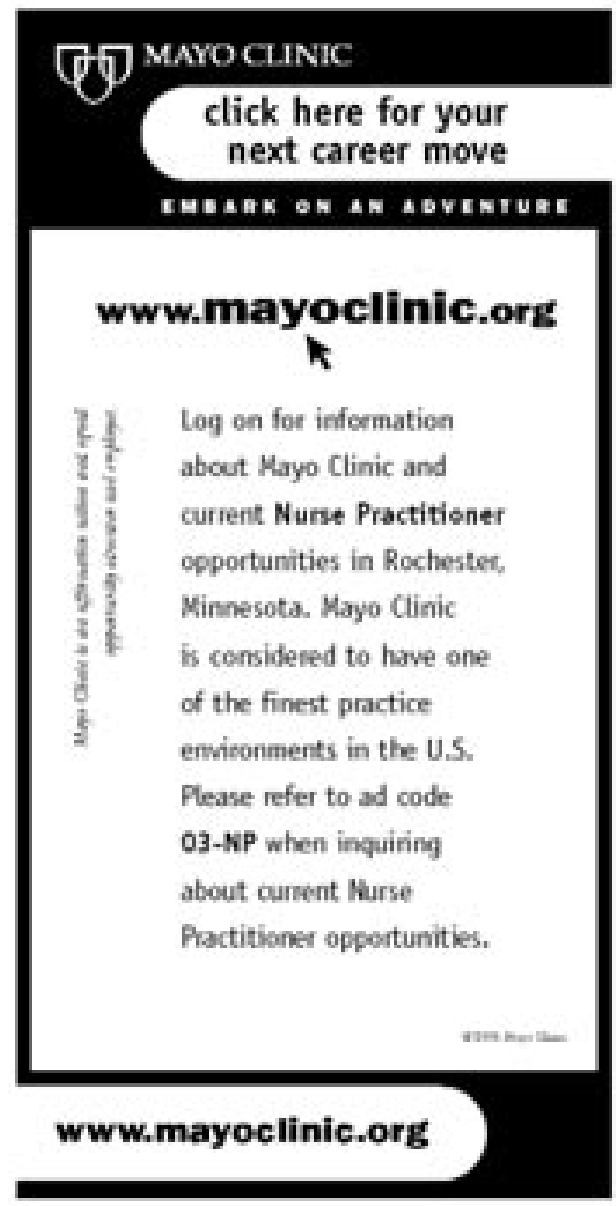

ment and billing requirements for nurse practitioners (NPS), physician assistants (PAs) and clinical nurse specialist (CNSS)-Balanced Budget Act of 1997 (DHHS publication No. AB-98-15). Washington, DC: U.S. Government Printing Office.

Horner, R.D., Paris, J.A., Purvis, JR., \& Lawler, F.H. (1991). Accuracy of the patient encounter and billing information in ambulatory care. The Journal of Family Practice, 33 (6), 593-98.

MedLearn (2000). Nurse practitioners guide to evaluation and management coding: A reimbursement guide. St. Paul, MN: Medical Learning.

Mundinger, M. 0., Kane, R. L., Lenz, E. R., Totten, T. M., Wei-Yann, T., Cleary, P. D., et al. (2000). Primary care outcomes in patients treated by nurse practitioners or physicians. Journal of the American Medical Association, 283 (1), 59-68.

Neale, J. (1999). Nurse practitioners and physicians: A collaborative practice. Clinical Nurse Specialist, 13 (5), 252-58.

Pearson, L.J (1999). Annual update of how each state stands on legislative issues affecting advanced nursing practice. The Nurse Practitioner, 24 (1), 16-24, 46.

Rapsilber, L., \& Anderson, E. (2000). Understanding the reimbursement process. The Nurse Practitioner, 25 (5), 36, 43,46,51-52, 54-56.

Safriet, B. F. (1992). Health care dollars and regulatory sense: The role of advanced practice nursing. Yale Journal of Regulation, 9 (2), 417-488.

Sullivan-Marx, E.M., \& Maislin, G. (2000). Comparison of nurse practitioner and family physician relative work values. Journal of Nursing Scholarship, 32 (1), 71-76.

Towers, J., Gillet, P., \& Goldblum, K. (2000). Forms facilitating primary care documentation. The Nurse Practitioner, 25 (11), 40-44, 49.

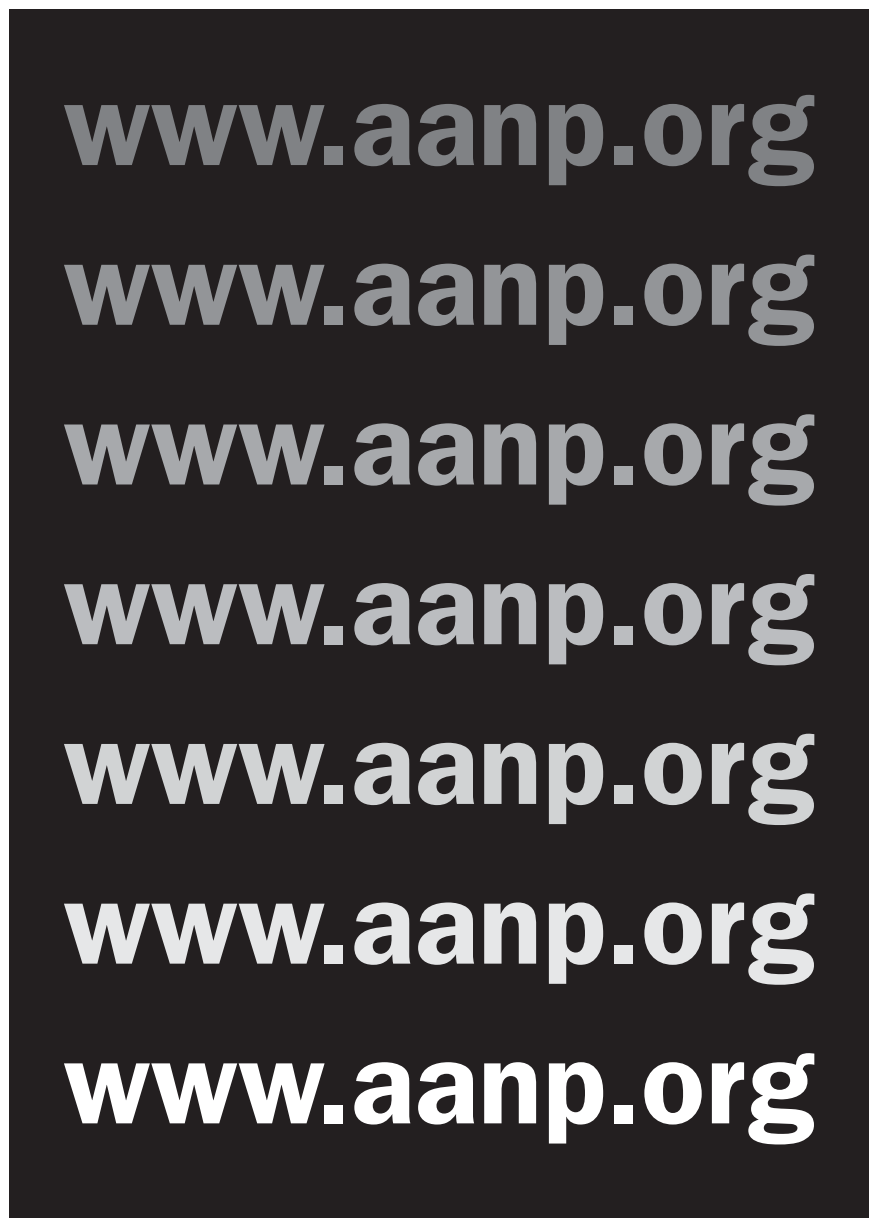

